\title{
Complex Sentences: Acquisition of Syntactic Connectives and the Semantic Relations They Encode ${ }^{1}$
}

\author{
Lois Bloom, Margaret Lahey, Lois Hood, Karin Lifter, and Kathleen Fiess
} Teachers College, Columbia University

CitATiOn: Bloom, L., Lahey, M., Hood, L., Lifter, K., \& Fiess, K. (1980). Complex sentences: Acquisition of syntactic connectives and the meaning relations they encode. Journal of Child Language, 7, 235-261. Reprinted in Bloom, L. (1991). Language development from two to three. New York: Cambridge University, pp. 261-288.

\begin{abstract}
The acquisition of connective forms and the meaning relations between connected clauses in the development of complex sentences is described for four children from two to three years of age. The major results of the study include the developmental interactions between syntactic connectives and meaning relations, and between these interactions and the discourse environments in which they occurred. The first syntactic connective the children learned, and, was the most general: semantically, and was used to encode conjunction with all of the different conjunction meaning relations in the order Additive $<$ Temporal $<$ Causal $<$ Adversative. Other connectives were semantically more specific, and were learned subsequently with different syntactic structures in the order Conjunction < Complementation < Relativization. These results are discussed in terms of FORM, relative linguistic complexity; CONTENT, the intersection of form with conceptual and semantic factors affecting acquisition; and USE, discourse cohesion.
\end{abstract}

Children begin to combine simple sentences to form complex sentences in the period from 2 to 3 years of age, and development of complex sentences involves learning aspects of form (syntactic connectives and syntactic structures); content (semantic relations between propositions); and use (discourse cohesion). The focus of the study reported here was on the acquisition of connective forms in complex sentences that theoretically combine the structures that underlie two simple sentences. ${ }^{2}$ Previous studies of the development of complex sentences have dealt most often with the forms of complex sentences (e.g., Limber, 1973; Menyuk, 1969). Few studies (e.g., Clancy, Jacobsen, \& Silva, 1976; Clark, 1970) have dealt with the intersection of linguistic form with semantic content, and none has considered the intersection of linguistic form with content and use in discourse. Further, most studies have described the language of children older than 3 years of age, who already have considerable knowledge of complex sentences (e.g., Bates, 1976; Clark, 1970, 1973; Ferreiro \& Sinclair, 1971; and Lust, 1976). The present study is concerned with the developmental interactions between connective forms and meaning relations and between these form-content interactions and the discourse environments in which they occurred.

\footnotetext{
${ }^{1}$ This study was supported by Research Grant HD 03828 from the National Institute of Child Health and Development; Fellowship F1-MH-30,001 from the National Institute of Mental Health, United States Public Health Service; and Research Grant Soc 74-28126 from the National Science Foundation to Lois Bloom. The study was published originally in Journal of Child Language, 7, 235-261.; reprinted in Bloom, L. (1991). Language development from two to three, New York: Cambridge University, pp. 261-288; and reformatted for this digital version with slight changes in organization and minor text editing.

${ }^{2}$ Because the focus of this paper was on the acquisition of syntactic connectives and the meaning relations they encode, complex sentences without connectives (e.g., "That's the bed Mommy bought me") and complementation (e.g., "Watch me draw a circle") were not included in this study but were examined in two separate studies of complementation. In addition, because the connective to has special status by virtue of its relation to verb stems in their nonfinite forms (Jespersen, 1961, vol. 5), to complements were also examined in a separate study.
} 


\section{SUBJECTS AND PROCEDURES}

The four children in this study-Eric, Gia, Kathryn, and Peter-were born in the 1960s, the first-born children of white, college-educated parents who lived in university communities in New York City. Their parents were native speakers of American English and their mothers were their primary caregivers. They were chosen as subjects with these qualifications in what turned out to be, in retrospect, a naive effort to come up with a 'homogeneous' population. Since parent education, birth order, and economic differences among children had been found to be sources of individual differences in speech and language in other studies, these were the minimal 'controls' that seemed feasible to ensure that the children would be similar in their language learning. ${ }^{3}$

Eric, Gia, and Kathryn were each visited in their homes for approximately eight hours over several days, every six weeks, by Lois Bloom; Peter was visited for approximately six hours every three weeks by Lois Hood and Patsy Lightbown. The visits occurred in the context of their daily activities and informal play with a familiar adult (the investigators) and, less often, with their mothers. The same or similar toys were brought to all the sessions, for the different children and for each child, in an effort to establish consistency in the home contexts among the children and over time. The observations were audio recorded, and the transcriptions included all speech by child and adult, along with descriptions of nonlinguistic context and behavior. ${ }^{4}$

The data base for this study consisted of five observations of Eric, five of Gia, five of Kathryn, and seven of Peter, beginning with the first observation at which connectives were produced and then including approximately every other observation until the child's third birthday. Information about the children's ages, total numbers of utterances, and mean length of utterance (MLU) in these observation sessions is presented in Table 1.

Table 1. Summary Description of Speech Samples

\begin{tabular}{|c|c|c|c|c|c|}
\hline \multirow{2}{*}{ Child } & \multirow{2}{*}{$\begin{array}{c}\text { Age Range } \\
\text { (months, weeks) }\end{array}$} & \multirow{2}{*}{$\begin{array}{c}\text { Total } \\
\text { Utterances }\end{array}$} & \multicolumn{3}{|c|}{ Mean Length of Utterance ${ }^{a}$} \\
\hline & & & Range & $\begin{array}{c}\text { Mean } \\
\text { Increment }\end{array}$ & S.D. \\
\hline Eric & $25,1-36,0$ & 15,713 & $2.63-3.49$ & .22 & .58 \\
\hline Gia & $25,2-34,2$ & 20,443 & $2.30-3.71$ & .47 & .55 \\
\hline Kathryn & $24,2-35,1$ & 20,025 & $2.83-4.23$ & .35 & .40 \\
\hline Peter & $25,3-38,0$ & 19,024 & $2.00-3.57$ & .22 & .53 \\
\hline
\end{tabular}

All child utterances that contained conjunctions, relative pronouns, and $w h$-pronouns provided the corpus for analysis. Sentence relations that extended cohesion across utterance boundaries (either in the same speaker turn, for example, "\# I carry this / and you carry that \#," or in two or more turns of different speakers, for example, “\# Your Mommy gave you a bottle? \# yes \# why? \# because I'm a little baby \#"), were included in the analysis if the child used a connective form (/ indicates utterance boundary; \# indicates turn boundary). All the speech events

3 However, see Bloom (1992) for a later appraisal of this decision.

4 The procedures for data collection and transcription are described in greater detail in Bloom (1970, pp. 234-9). See, also, Bloom, Lightbown, and Hood (1975) and conventions for transcription of child language recordings, App. A, in Bloom \& Lahey (1978). The speech samples from Eric, Gia, and Kathryn were collected and transcribed by Lois Bloom. The speech samples from Peter were collected and transcribed by Lois Hood and Patsy Lightbown, who took turns interacting with Peter and taking notes on the situational context and behavior. The transcriptions of the Eric, Gia, Kathryn, and Peter data are stored for access by other researchers in the Special Collections at the Gottesman Memorial Libraries, Teachers College, Columbia University; transcripts of the Peter data are also part of the CHILDES database, the Child Language Data Exchange System, Carnegie-Mellon University. 
were examined and coded according to their (1) connective forms, (2) semantic relations, (3) syntactic structures, and (4) cohesion relations between connected clauses.

The procedures for identifying the connective forms and the discourse environments for cohesion relations were relatively straightforward because they depended upon identifying formal regularities in the data; that is, whether or not one or another connective was said and whether or not two connected clauses extended across utterance boundaries. On the other hand, the identification of semantic relations between clauses was an interpretive process. Interpretation was centered on the question, What is the meaning of two clauses in relation to each other?, given

(1) The meaning of a first clause, /maybe you can bend the man -

(2) the meaning of the second clause, - he can sit /

(3) the fact that the two clauses are connected by so in the sentence, / maybe you can bend the man so he can sit /

(4) the fact that the child was trying to bend a toy wire figure and then subsequently put it on a train car.

This process of interpreting the semantic relations between clauses in complex sentences is a continuation of the procedures used in earlier studies of the semantic relations between words in children's simple sentences. In earlier child language data, when MLU progresses from 1.o to 2.0, the semantic relations between words in simple sentences can be inferred from information in the situational context. For example, "Mommy pigtail," in which Mommy is combing the child's hair, can be interpreted as the semantic relation agent-object. The categories of semantic relations in early sentences, such as recurrence, possession, agent-object, and action-object (described in Bloom, 1970; Brown, 1973; Schlesinger 1971) were derived from the child language data in this way, on the basis of inferences from contextual cues, rather than being imposed upon the child language data on the basis of inferences from the adult model. Similarly, the semantic relations between connected clauses in complex sentences were interpreted, in the later child language data described in this study, on the basis of the relation between what was said and the situational context in which utterances occurred, rather than according to the forms the children used (i.e., connectives or verbs) and their meanings in adult speech. Although certain semantic relations were expected in the data, for example, causality and temporal relations-in part because the children were using such connectives as because, and, and then-the meanings of these connectives were not always transparent. The meanings of the semantically more general connectives, that is, and, that, and what, were even less transparent. After repeated passes through the data, certain meaning relations between clauses emerged as being more consistent and developmentally relevant than others, and these categories of meaning relations form the major results of this study.

Two methodological issues bear on the results reported here: ambiguity and/or equivocal interpretation, and subcategorization. The first issue, ambiguity and/or equivocal interpretation was perhaps the most problematic. The procedures for interpretation followed a general rule of cumulative semantic complexity (after Brown, 1973): If an utterance (A) contained the same relation as another utterance (B) plus something more, then the utterance (A) was interpreted in terms of that something more. For example, the utterance "You push up and it turn" was said as the child played with a toy with parts that could both be pushed up and turned. Only a dependency relation that was temporal between the clauses "you push up" and "it turn" could be inferred with confidence; that is, pushing was neither necessary nor sufficient for turning, and so the utterance was categorized as temporal rather than causal. In the utterance "Maybe you can bend him so he can sit," there was a temporal relation between the clauses plus something more, a causal dependency relation; that is, the man could not sit unless he was bent, and the utterance was categorized as causal rather than temporal based upon the cumulative principle.

Ultimately, the reliability of judgments of interpretation was decided by consensus. Once the final semantic categorization was obtained (the eight semantic relations reported below), the reliability of coding was tested as 
follows: A sample of 100 utterances was drawn from each of two observations from each of the individual children and coded independently by three of the investigators. The proportions of agreement between independent codings ranged between .80 and .90 .

The issue of subcategorization had to do with the fact that several categories of semantic relations were not themselves homogeneous. Even finer distinctions were observed in addition to the major meanings that formed the results of this study. Several of these subcategorizations are described in separate studies. For example, causal utterances expressed both cause-effect and effect-cause orders (as described in Hood \& Bloom, 1979). With other subcategorizations, procedures for coding have not yet been worked out. For example, temporally related clauses were either simultaneous or sequential, or some overlapping combination of the two, but these distinctions could not always be reliably determined. Still other subcategorizations either occurred too infrequently to be considered important or showed no developmental change.

Given these two qualifications on the interpretation of meaning relations (ambiguity and/or equivocal interpretation, and subcategorization) it was possible to identify the major semantic relations between clauses in an average of .87 of the children's complex sentences. The semantic relations that were either anomalous or otherwise uninterpretable made up the remaining .13 of the data (range .08 to .18 for the several observations of the four children).

In order to establish that a form (i.e., a connective or syntactic structure) or a meaning relation or a connectivemeaning relation interaction was acquired, a criterion of productivity was set in advance: The occurrence of five or more different utterances in each of at least two successive observations of a particular child was counted as evidence of productivity for the child (see Bloom, Lightbown, \& Hood, 1975; and Bloom \& Lahey, 1978, for discussions of productivity and criterion-referenced descriptions of language acquisition, respectively).

\section{RESULTS}

Connective forms were used primarily in three different ways. First, nonconnective use involved the use of certain homonymous forms, such as what, where, that, and like in nonconnective contexts, such as "what doing," "where doggie," "that my shoe," and "like this." Such homonymous forms have both connective and nonconnective uses. They were learned first in their nonconnective contexts, and with the exception of $w h a t$, they were the last forms to be used as connectives. In contrast, other connective forms, such as and, then, and because, were nonhomonymous and were the first forms used as connectives.

Second, contextual use involved the use of and to chain a child utterance to a nonlinguistic event that was either something the child did or saw in the context, for example:

(1) K IV

(K had opened a box of toy figures and taken them out; picking up box of furniture) and let's see dis.

(2) E VI

(E picks up puppet, puts it in box with other puppets) and I close them.

The third use of connectives was the focus of the present study: the use of syntactic connectives to either connect two constituents within a sentence phrase (phrasal structures) or to connect two related clauses (sentential structures). Most frequently, the constituents in phrasal structures were the noun phrase of the predicate complement, for example:

(3) G VIII

(Mother and Lois talking about redecoration in Gia's home)

and Mommy's gonna get me chair and table. 
The use of and in sentence subject phrases was relatively rare, for example:

\section{(4) G VII}

(telling Lois about yesterday's visit to Grandma's) Uncle Paul and Grandma no there.

The distribution of contextual, syntactic, and other uses of connectives 5 is presented in Table 2. The children began to use contextual and and syntactic and at the same time, except for Kathryn who used contextual and before using connectives syntactically. The syntactic use of connectives in phrasal and sentential structures is described in the results that follow.

Table 2. The Frequency of Structures with Connectives

\begin{tabular}{|c|c|c|c|c|c|}
\hline \multirow{2}{*}{$\begin{array}{l}\text { Child, } \\
\text { Sample }\end{array}$} & \multirow{2}{*}{$\begin{array}{c}\text { Age } \\
\text { (months, } \\
\text { weeks) }\end{array}$} & \multirow{2}{*}{$\begin{array}{l}\text { Number and } \\
\text { Proportion of } \\
\text { Utterances }\end{array}$} & \multicolumn{3}{|c|}{$\begin{array}{l}\text { Proportion of Utterances with } \\
\text { Connectives }\end{array}$} \\
\hline & & & Syntactic & Contextual & Other \\
\hline \multicolumn{6}{|l|}{ Eric } \\
\hline $\mathrm{V}$ & 25,1 & 9 (.003) & $.22^{\mathrm{a}}$ & $.44^{\mathrm{a}}$ & $.33^{\mathrm{a}}$ \\
\hline VI & 26,3 & $169(.046)$ & .57 & .17 & .27 \\
\hline VIII & 29,3 & 296 (.12) & .54 & .19 & .26 \\
\hline $\mathrm{X}$ & 33,0 & $234(.11)$ & .66 & .21 & .13 \\
\hline XII & 36,0 & $361(.10)$ & .65 & .14 & .20 \\
\hline \multicolumn{6}{|l|}{ Gia } \\
\hline $\mathrm{V}$ & 25,2 & $20(.007)$ & .80 & - & $.20^{\mathrm{a}}$ \\
\hline VI & 27,1 & $122(.04)$ & .52 & $.02^{\mathrm{a}}$ & .46 \\
\hline VII & 28,2 & $76(.04)$ & .63 & $.02^{\mathrm{a}}$ & .35 \\
\hline VIII & 30,0 & 224 (.05) & .71 & .06 & .23 \\
\hline XI & 34,2 & $347(.08)$ & .66 & .10 & .24 \\
\hline \multicolumn{6}{|l|}{ Kathryn } \\
\hline III & 24,2 & $7(.002)$ & - & 1.0 & - \\
\hline IV & 26,1 & 69 (.02) & .71 & .10 & .19 \\
\hline VI & 29,1 & $181(.06)$ & .78 & .13 & .09 \\
\hline VIII & 32,1 & $213(.08)$ & .90 & $.01^{\mathrm{a}}$ & .08 \\
\hline $\mathrm{X}$ & 35,1 & $615(.12)$ & .73 & .06 & .20 \\
\hline \multicolumn{6}{|l|}{ Peter } \\
\hline $\mathrm{X}$ & 27,0 & $60(.02)$ & .53 & $.07^{\mathrm{a}}$ & .40 \\
\hline XII & 28,2 & $33(.01)$ & .42 & - & .58 \\
\hline XIV & 30,0 & $86(.04)$ & .65 & .10 & .24 \\
\hline XVI & 31,2 & $94(.04)$ & .65 & .09 & .27 \\
\hline XVIII & 33,3 & 128 (.05) & .72 & .05 & .23 \\
\hline XIX & 35,0 & 338 (.14) & .61 & .10 & .29 \\
\hline $\mathrm{XX}$ & 38,0 & $234(.10)$ & .77 & .03 & .21 \\
\hline
\end{tabular}

5 Other uses of connectives included idiomatic verb phrases such as "come and go," "go and get," and "stand and wait" and sentence fragments such as "red and blue" and "milk and cookies." 


\section{Syntactic Connectives}

The connective forms (conjunctions, wh-pronouns, and relative pronouns) used most frequently by the four children combined were and, because, what, when, and so; the less frequently used connective forms were and then, but, if, that, and where (Hood, Lahey, Lifter, \& Bloom, 1978). The sequence in which the connectives became productive for each child individually is presented in Figure 1, according to age.

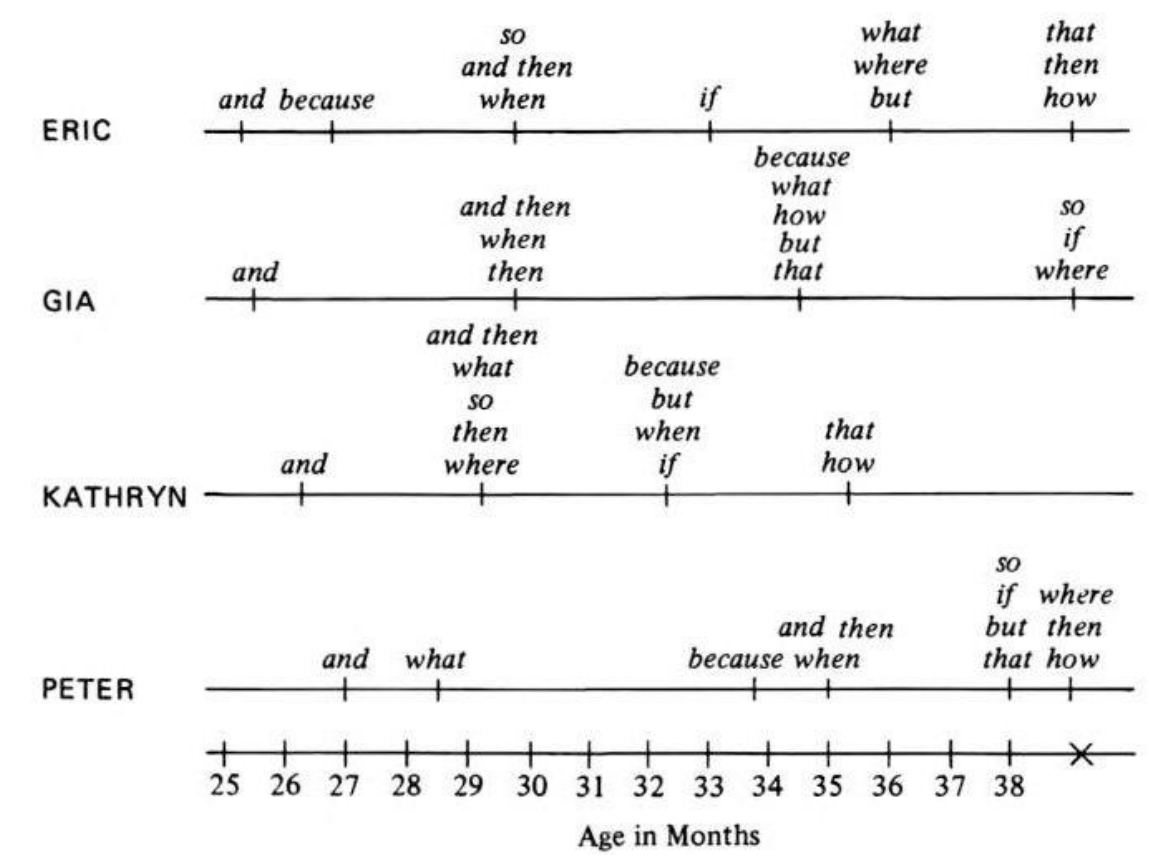

Figure 1. Sequence of emergence of syntactic connectives for the individual children. (Those connectives above the $\mathrm{X}$ on the abscissa appeared sporadically but were not productive within the age period studied.)

The developmental sequence was rank ordered for each child. When two or more connectives became productive in the same sample, ranks were determined according to proportional use, and the ranks were split if a difference in proportion was $\leq .05$. The rank orders were averaged across the four children, for only those connectives that were used productively for at least two of the children. The average rank order is plotted in Figure 2 in relation to average age of connective productivity ${ }^{6}$ with indication of the range in age of emergence among the children. When a connective was not productive for a child, although it occurred, that connective was assigned a later rank than the forms that were productive for that child. Spearman rank-order correlations were computed by comparing the rank orders of connective emergence for all combinations of pairs for the four children. Of the six correlation coefficients computed (range .45 to .84), only one comparison was significant, which confirmed the variation among the children in the rank order of emergence seen in Figure 1. For example, then was productive early for Kathryn and Gia and never became productive for Eric and Peter; where was productive early for Kathryn, late for Eric, and never became productive for Gia and Peter; what became productive very early for Peter and later for the other children. Thus, Figure 2 is intended only as a general summary of average rank order and average age of emergence of connectives. There was considerably more variation in age of emergence than in rank order. And was the first connective to emerge, and the remaining connectives, by and large, emerged subsequently, although at different ages for different children.

6 The age at the last sample was used as the estimate of age of emergence for those connectives that occurred in the data but did not become productive. 


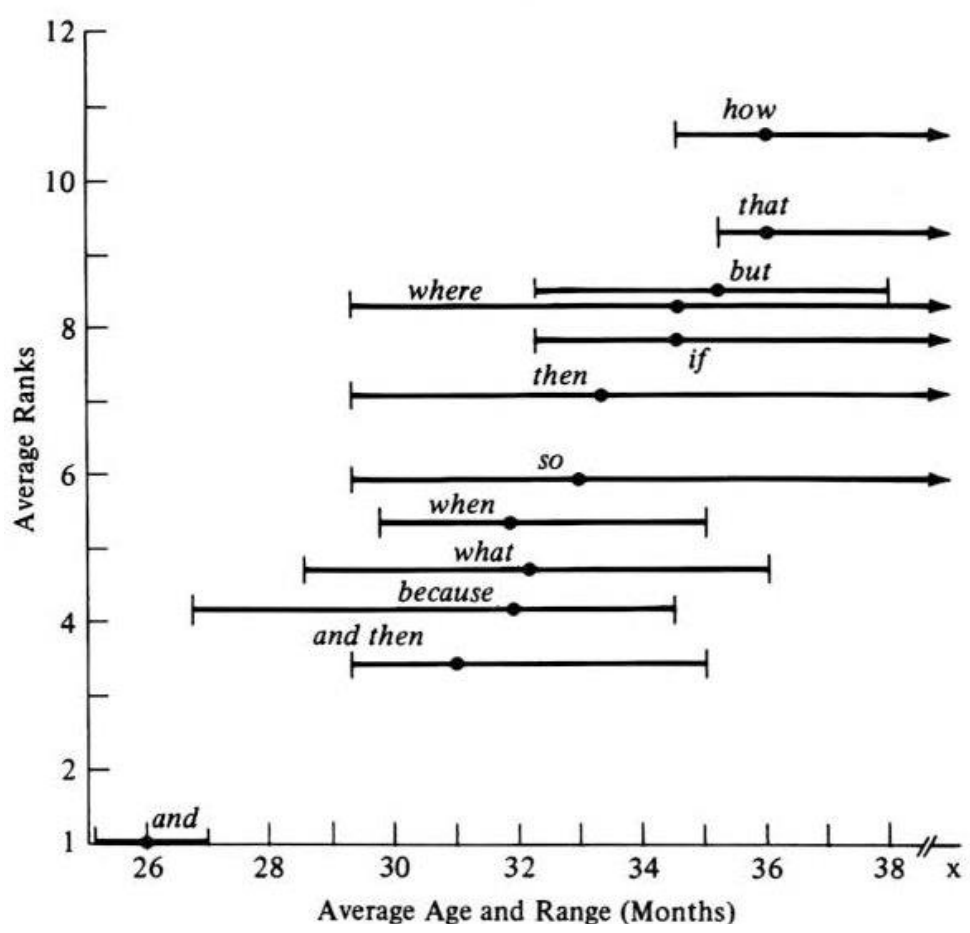

Figure 2. Developmental rank order of connective forms. (X on the abscissa indicates the expectation that the connective became productive for the remaining child(ren) eventually, although not within the time span of the study reported here.)

\section{Semantic Relations}

Eight major meaning relations were observed; these are described below, with examples.7

Additive. In additive relations, two events and/or states were joined without an added dependency relation between them. Each clause was meaningful by itself; the combination of the two clauses did not create a meaning that was anything other than the meaning of each clause separately. Additive relations were expressed when the child carried out successive actions and chained each clause with each action.

\section{(5) KVI}

Can you carry this for me very carefully? Maybe you can carry that and I can carry this.

(6) E VIII

(looking at picture in book).

They're taking a vacuum cleaner and puppy dog's running.

Temporal. In a temporal relation there was a dependency between events and/or states which involved temporal sequence or simultaneity. The utterance was not chained to successive actions, as could be the case in additive sentences; that is, at least one of the events was not concurrent with the utterance.

7 One other semantic relation was observed but never became productive for any of the children: manner, for example, "I wanta do it like you did." 
(7) KIV

(talking about a visit to her friend, Jocelyn) Jocelyn's going home and take her sweater off.

(8) K VI

(pushing toy car to hall)

I going this way to get the groceries then come back.

(9) PXX

(Peter and Patsy looking for blue block;

Patsy suggests that it's under Peter; Peter looks; it isn't there)

It's not anywhere/you better look for it/when you get back home.

Causal. In a causal relation there was a dependency between two events and/or states which was most often intentional and/or motivational. One clause referred to an intended or ongoing action or state, and the other clause gave a reason or result (Hood \& Bloom, 1979).

(10) K VI

(giving bendable figure to Lois)

Maybe you can bend him so he can sit.

(11) E VIII

(going toward slide disks)

Get them cause I want it.

(12) PXX

(telling about a friend who hurt her foot) She put a band aid on her shoe and it maked it feel better.

Adversative. In this category the relation between two events and/or states was one of contrast. Most often the relation between the clauses was one of opposition, in which one clause negated or opposed the other, or of exception, in which one clause qualified or limited the other.

(13) P XVIII

(trying to get trunk part in car)

(then trying to fit hood part which does fit)
It can't.

and this can go here.

(14) KX

(telling and demonstrating how she sleeps on the sofa) cause I was tired/but now I'm not tired.

Object Specification. In this category the two clauses combined described an object or person mentioned in the first clause. The most common descriptions of the object or person concerned function, place, or activity.

(15) G XI

(Gia using toy telephone)

Mommy: Who'd you call?

The man who fixes the door.

(16) KX

( $\mathrm{K}$ comes into room with fishing pole)

Lois: What's that?

It looks like a fishing thing and you fish with it.

Epistemic. The dependency relation in utterances in this category involved certainty or uncertainty on the part of the person named in the first clause (the child most often) about a particular state of affairs named in the second clause.

(17) E XII

(playing with toy family figures)

Lois: What do you think this baby's name is? I don't know what her name is. 
(18) KVI

(referring to living room of dollhouse) I think that that's where the baby will go.

Notice. Utterances in this category called attention to a state or event named in the second clause.

(19) $\mathrm{KX}$

(putting finger puppet on her toe)

Watch what I'm doing.

(20) G XI

(showing Lois some candy)

Look what my Mommy got me.

Other. These were complements, other than epistemic and notice complements, with verbs of communication or the copula primarily.

(21) K VIII

(after showing Lois how to turn and fall)

That what you can do.

(22) E XII

(Eric had just awakened, when Lois entered room) Tell Iris that I wet my bed.

The relative frequency of these semantic relations at each observation is presented in Table 3 for each child. The sequence of emergence of the categories of meaning relations is plotted for each child individually, according to age, in Figure 3.

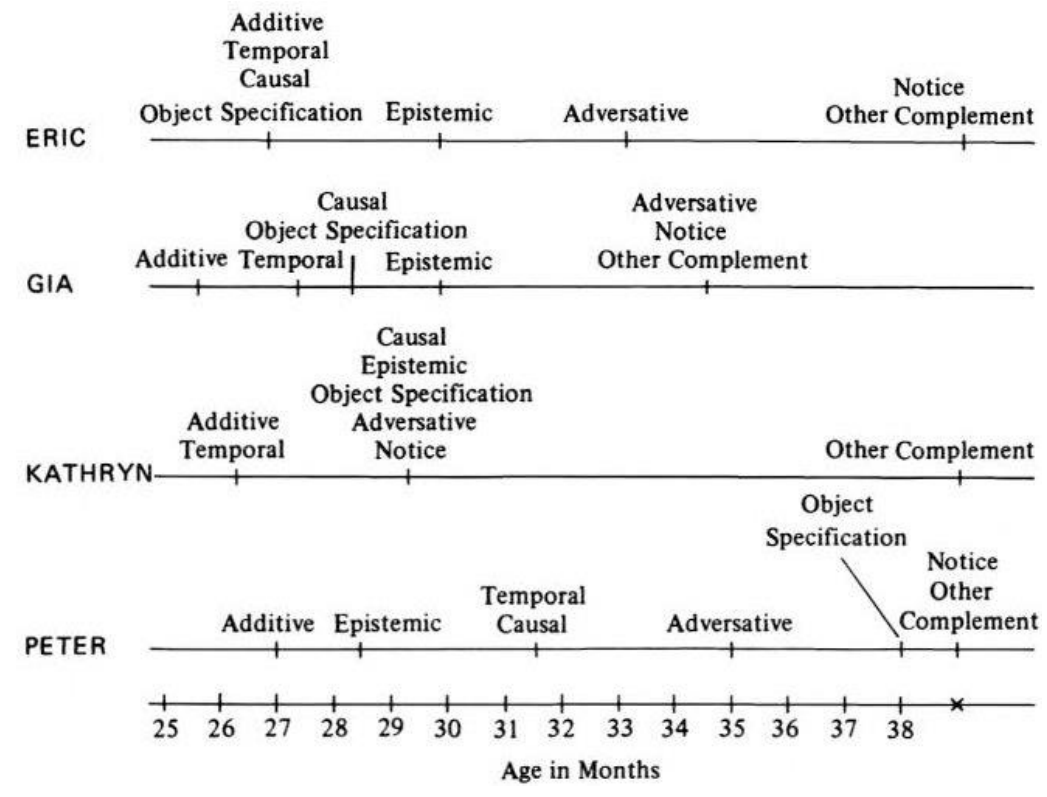

Figure 3. Sequence of emergence of semantic relations for the individual children. (The connectives above the $\mathrm{X}$ on the abscissa were not productive within the age period studied). 
Table 3. Proportional Distribution of Utterances in the Categories of Clausal Meaning Relations, Eric and Gia

\begin{tabular}{|c|c|c|c|c|c|c|c|c|c|c|}
\hline \multirow[b]{2}{*}{ Category } & \multicolumn{10}{|c|}{ Subjects and Samples } \\
\hline & E V & E IV & E VIII & EX & E XII & G V & G VI & G VII & G VIII & G XI \\
\hline Additive & $\mathrm{np}^{\mathrm{a}}$ & .57 & .50 & .44 & .34 & 1.00 & .81 & .60 & .41 & .26 \\
\hline Temporal & - & .21 & .19 & .08 & .05 & - & .13 & .23 & .36 & .23 \\
\hline Causal & - & .13 & .17 & .30 & .36 & - & $\mathrm{np}$ & .08 & .14 & .27 \\
\hline Adversative & - & $\mathrm{np}$ & .05 & .05 & .06 & - & - & $\mathrm{np}$ & $\mathrm{np}$ & .03 \\
\hline Manner & - & - & $\mathrm{np}$ & - & $\mathrm{np}$ & - & - & - & - & $\mathrm{np}$ \\
\hline $\begin{array}{l}\text { Object } \\
\text { specification }\end{array}$ & np & .05 & .06 & .06 & .06 & - & np & .05 & .03 & .7 \\
\hline Epistemic & - & - & .03 & .06 & .12 & - & - & - & .04 & .05 \\
\hline Notice & - & - & - & - & $\mathrm{np}$ & - & - & - & - & .05 \\
\hline $\begin{array}{l}\text { Other } \\
\text { complement }\end{array}$ & - & - & - & $\mathrm{np}$ & $\mathrm{np}$ & - & - & - & - & .02 \\
\hline Total & 2 & 96 & 161 & 155 & 234 & 16 & 64 & 111 & 160 & 229 \\
\hline
\end{tabular}

Table 3, continued, Kathryn and Peter

\begin{tabular}{|c|c|c|c|c|c|c|c|c|c|c|c|c|}
\hline \multirow[b]{2}{*}{ Category } & \multicolumn{12}{|c|}{ Subjects and Samples } \\
\hline & K IV & K VI & K VIII & KX & P VIII & P X & P XII & P XIV & P XVI & P XVIII & P XIX & $\mathrm{PXX}$ \\
\hline Additive & .80 & .43 & .23 & .17 & $\mathrm{np}$ & .78 & .43 & .80 & .43 & .60 & .47 & .22 \\
\hline Temporal & .16 & .23 & .17 & .13 & - & $\mathrm{np}$ & - & $\mathrm{np}$ & .20 & .08 & .17 & .10 \\
\hline Causal & - & .16 & .43 & .40 & - & - & - & np & .11 & .22 & .19 & .29 \\
\hline Adversative & $\mathrm{np}$ & .04 & .05 & .17 & - & - & - & - & np & np & .06 & .03 \\
\hline Manner & - & - & $\mathrm{np}$ & $\mathrm{np}$ & - & - & - & - & $\mathrm{np}$ & - & $\mathrm{np}$ & $\mathrm{np}$ \\
\hline $\begin{array}{l}\text { Object } \\
\text { specification }\end{array}$ & - & - & $\mathrm{np}$ & $\mathrm{np}$ & - & - & - & - & np & - & np & np \\
\hline Epistemic & $\mathrm{np}$ & .06 & .09 & .05 & - & $\mathrm{np}$ & $\mathrm{np}$ & - & $\mathrm{np}$ & - & $\mathrm{np}$ & .04 \\
\hline Notice & - & .05 & $\mathrm{np}$ & .04 & - & - & .50 & .11 & .18 & $\mathrm{np}$ & .08 & .28 \\
\hline $\begin{array}{l}\text { Other } \\
\text { complement }\end{array}$ & - & - & $\mathrm{np}$ & $\mathrm{np}$ & - & - & - & - & - & - & - & np \\
\hline Total & 49 & 142 & 192 & 450 & 2 & 32 & 14 & 56 & 61 & 92 & 206 & 179 \\
\hline
\end{tabular}

${ }^{\mathrm{a}} \mathrm{np}=$ nonproductive; $-=$ relation did not occur.

The sequence in which the meaning relations first became productive was rank ordered for each child. When more than one relation was productive within a sample, rank order was decided according to relative proportion, and ranks were split if a difference in proportion was $<.05$. The average order of acquisition for the four children was determined by averaging the individual rank orders for those categories that were productive for at least two of the children. This average rank order is plotted in Figure 4 in relation to average age, ${ }^{8}$ with indication of the range in age of emergence among the four children.

8 The age at the last sample was used as the estimate of age of emergence for those meaning relations that occurred in the data but did not become productive. 
Although the acquisition order was based on the meaning relations that became productive for at least two of the children, all the meaning relations were observed (although they were not necessarily productive) in the speech samples for each child. When a category of relations was not productive for a child, that category was assigned a later rank than the productive categories for that child. Spearman rank-order correlations were computed by comparing the rank order of emergence for all combinations of pairs for the four children. Six correlation coefficients were computed; they ranged from .75 to .95 , with $p<.05$ for four of the six comparisons. The largest

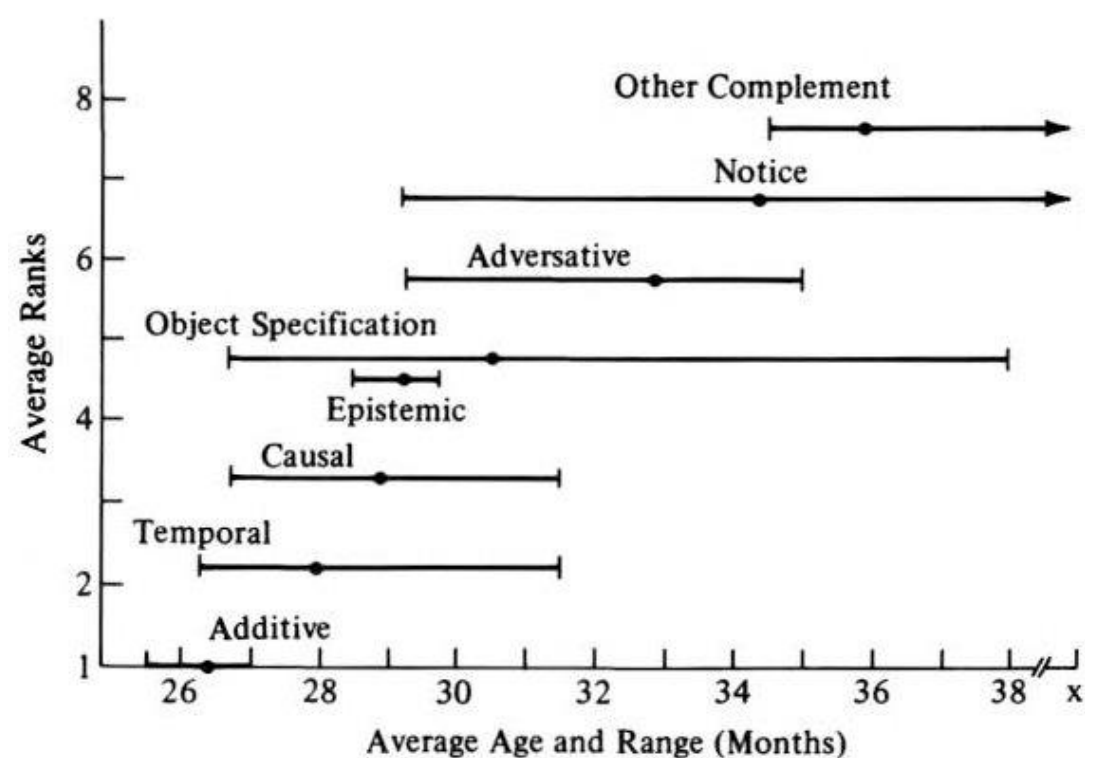

Figure 4. Developmental rank order of semantic relations. X on the abscissa indicates the expectation that the meaning relation became productive for the remaining child(ren) eventually, although not within the time span of the study reported here.

differences occurred in the rank order of the epistemic relation which emerged much earlier for Peter than for the other children. With epistemic eliminated from the rank order, pairwise comparisons yielded correlation coefficients ranging from .87 to .95 , with $p<.05$ for all six comparisons. Thus the children were quite similar to one another in terms of order of emergence of the meaning relations, although the meaning relations emerged at different ages for the different children. Thus, the meaning relations were acquired sequentially over the course of 10 months, with far more similarity in rank order of meaning relations than in rank order of connectives.

\section{Intersection of Connectives and Semantic Relations}

Eight meaning relations were expressed with the 12 connectives that were productive in these complex sentences. Although it was statistically possible to have 96 intersections of content (the meaning relations between clauses) with form (the syntactic connectives used to connect clauses), only 45 intersections actually appeared in the data. However, only 10 of these intersections were productive for at least three of the children, and 15 were productive for at least two of the children. Two of the connectives, where and how, were productive overall but did not become productive with particular meaning relations. 


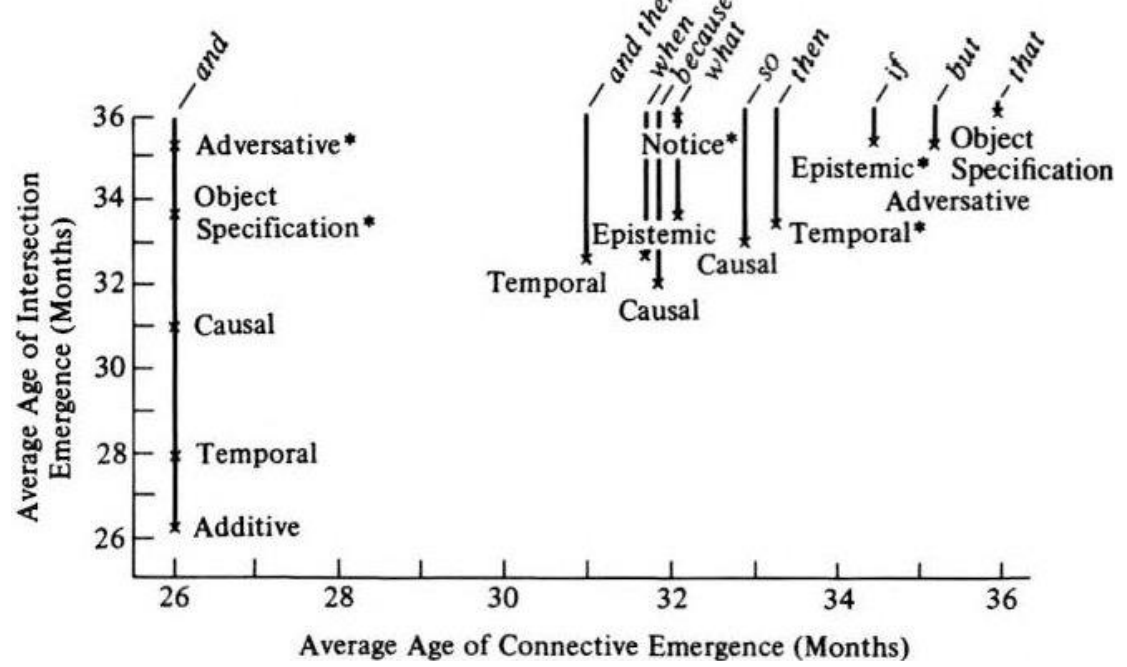

Figure 5. The development of the intersection of connectives with semantic relations. ${ }^{*}$ Indicates intersections that were productive for only two of the four children. (Where and how did not become productive with any semantic relations.)

The development of the intersection of connectives with semantic relations is presented in Figure 5 . The average ages of emergence of the connectives are displayed along the horizontal axis. The $\mathrm{x}$ indicates the average age of the intersection of a connective with a meaning relation. And was the first and most frequent connective used and was also used with more different meaning relations than were the other connectives (e.g., additive, temporal, and causal). With a less stringent criterion of productivity (i.e., productive for at least two rather than three of the children), and was observed with object specification and adversative as well. Other connectives (e.g., because, so, but, when, etc.) appeared after and and were each used selectively with different meaning relations.

\section{Syntactic Structures}

The children acquired complex sentences with connectives with three syntactic structures: conjunction, relativization, and complementation. There was a strong relationship between semantic relations and syntactic structures. Conjunction was used with utterances that expressed additive, temporal, causal, and adversative relations. Conjunction was also used occasionally to express object specification. Complementation was used with utterances that expressed epistemic and notice relations and occasionally for object specification. Relativization was used only to express object specification. The sequence of acquisition was, in general, conjunction < complementation < relativization. Conjunction developed first for all children, with three conjunction meanings in the order: additive $<$ temporal $<$ causal. The fourth conjunction meaning, adversative, appeared 4 months later (see Figure 4) along with other, later-appearing structures. ${ }^{9}$

Complementation developed after conjunction in the order epistemic < notice < other, except for Kathryn, who acquired epistemic, notice, and complementation with object specification at the same time. Verb complements with syntactic connectives entailed $w h$-pronominalization of a constituent (subject or object) in the complement sentence (e.g., "Watch what I'm doing" and "Look what my mommy got me").

Relativization with that or wh-pronominalization of an antecedent noun, for example, "The man who fixes the door," was the last structure to appear, was always infrequent, and was used with only one meaning relation (object specification). The meaning relation object specification was encoded with all three of the structures by

9 The terms used for the four meanings of conjunction conform with terminology used by Halliday and Hasan (1976). 
one or another of the four children: Gia and Peter used only relativization; Eric used conjunction first and then relativization; Kathryn used all three in the order complementation $<$ relativization < conjunction.

Table 4. Frequency and Proportion of Sentential Structures in the Semantic Categories of Conjunction

\begin{tabular}{|c|c|c|c|c|}
\hline \multirow{2}{*}{$\begin{array}{l}\text { Child } \\
\text { and } \\
\text { Session }\end{array}$} & Additive & Temporal & Causal & Adversative \\
\hline & $n(p)$ & $n(p)$ & $n(p)$ & $n(p)$ \\
\hline \multicolumn{5}{|l|}{ Eric } \\
\hline VI & $55(.36)$ & $20(.35)$ & $12(.83)$ & $\mathrm{np}^{\mathrm{a}}$ \\
\hline VIII & $80(.63)$ & $30(.50)$ & $27(.85)$ & $8(1.0)$ \\
\hline $\mathrm{X}$ & $68(.44)$ & $13(.38)$ & $46(.98)$ & $8(.88)$ \\
\hline XII & $80(.56)$ & $11(.82)$ & $84(.90)$ & $15(.80)$ \\
\hline \multicolumn{5}{|l|}{ Gia } \\
\hline $\mathrm{V}$ & $16(.13)$ & - & - & - \\
\hline VI & $52(.08)$ & $8(.50)$ & np & np \\
\hline VII & $67(.31)$ & $26(.42)$ & $9(.67)$ & np \\
\hline VIII & $66(.32)$ & 57 (.95) & $22(.73)$ & $\mathrm{np}$ \\
\hline XI & $59(.56)$ & $52(.89)$ & $61(.92)$ & $8(.75)$ \\
\hline \multicolumn{5}{|l|}{ Kathryn } \\
\hline IV & $39(.46)$ & $8(.25)$ & $\mathrm{np}$ & $\mathrm{np}$ \\
\hline VI & $60(.63)$ & $33(.70)$ & $23(.87)$ & $5(.80)$ \\
\hline VIII & $44(.57)$ & $33(.73)$ & $82(.91)$ & $9(1.0)$ \\
\hline $\mathrm{X}$ & $78(.56)$ & $59(80)$ & $182(.97)$ & $78(.96)$ \\
\hline \multicolumn{5}{|l|}{ Peter } \\
\hline $\mathrm{X}$ & $25(.24)$ & $\mathrm{np}$ & - & - \\
\hline XII & $6(.50)$ & - & $\mathrm{np}$ & - \\
\hline XIV & $45(69)$ & $\mathrm{np}$ & $\mathrm{np}$ & - \\
\hline XVI & $26(.35)$ & $12(.50)$ & $7(.57)$ & np \\
\hline XVIII & $55(.36)$ & $7(.71)$ & $20(1.0)$ & $\mathrm{np}$ \\
\hline XIX & $96(.54)$ & $34(.68)$ & $39(.84)$ & $12(.83)$ \\
\hline XX & $40(.35)$ & $17(1.0)$ & $52(.93)$ & $6(.83)$ \\
\hline
\end{tabular}

${ }^{\mathrm{a}} \mathrm{np}=$ nonproductive $;$ - indicates none .

Within conjunction, both phrasal structures (connected constituents within a phrase) and sentential structures (connected clauses within a sentence) were distributed differentially across the four meanings of conjunction. These results are presented in Table 4 in terms of the number and relative proportion of sentential (versus phrasal) conjunction. Both phrasal and sentential structures were acquired at the same time, with additive conjunction, for all the children except Gia, who acquired phrasal structures first. While the relative frequencies 
of phrasal and sentential structures in additive conjunction remained essentially the same across time, there was a developmental increase in the proportion of sentential structure in temporal conjunction. Sentential structures predominated at all times with all the children for causal and adversative conjunction.

\section{Cohesion Relations in Discourse}

While the syntactic connective was always part of a child utterance, the connective was sometimes used to connect relations that extended across utterance boundaries. When both parts of the relation occurred within one or across two consecutive child utterances, the cohesion was child-child. That is, both parts of the meaning relation, before and after the connective, were said by the child, for example, "And there's my eye/and there's my feet." For two of the conjunction meanings (additive and temporal), for object specification, and for complementation, cohesion was child-child .90 of the time, averaging across samples and across children.

When the two parts of the semantic relation before and after the connective occurred across two or more different speaker turns, the cohesion was either adult-child or child-adult-child, for example, "\# Maybe he'll ride the horse \# Yeah, when he comes in \#." The only two meaning relations with cohesion that involved an adult utterance more than 0.20 of the time were causality and adversative (see Figure 6). For all children, the first appearance of the causality meaning relation occurred with child-child cohesion at least twice as often as with adult cohesion. The first appearance of the adversative relation occurred with child-child cohesion at least twice as often for two of the children; of Gia's first three adversative utterances, two were child-child, and Peter's first two utterances were one of each.

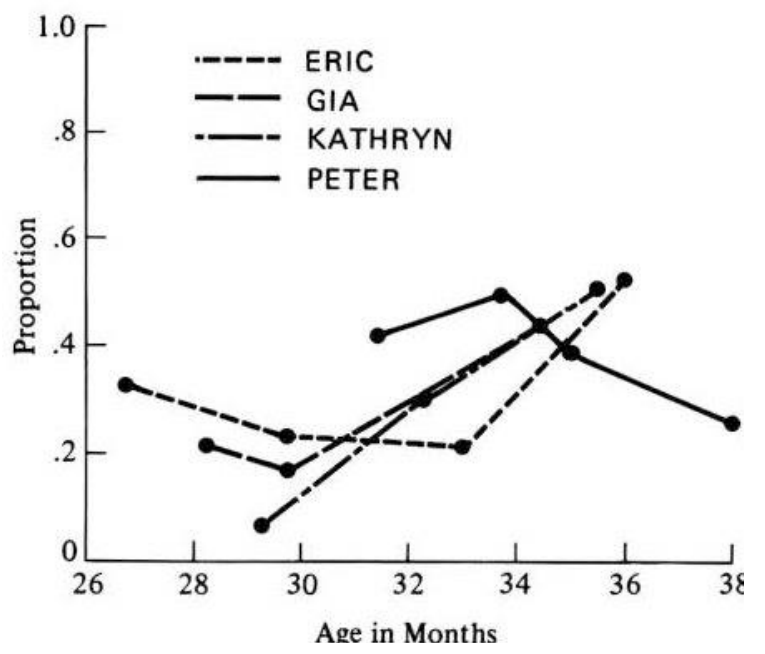

Figure 6. Proportion of the combined causality and adversative relations with cohesion involving an adult speaker turn.

A second cohesion analysis was performed with causality and adversative utterances to determine the use of the different syntactic connectives with the different cohesion patterns. With causality, as seen in Table 5, more different connectives were used with child-child cohesion. The most frequent connective used with adult-child and child-adult-child cohesion was because (most often in response to a why question). However, because was used in both child-child cohesion and cohesion involving an adult utterance from the beginning by Eric and Kathryn. Peter's first two instances of because were used in adult cohesion, but in the next sample, because was used as often in child as in adult cohesion. While Gia's first instances of because were used in adult cohesion, the connective was not used at all in the next sample and was used frequently in both cohesion patterns by Gia XI. Thus, for all the children, the first productive use of because was in both cohesion patterns. All the other connectives were used overwhelmingly with child-child cohesion. 
Table 5. Frequency of Causal Connectives According to Child and Adult Cohesion

\begin{tabular}{|c|c|c|c|c|c|c|c|c|c|}
\hline \multirow[b]{3}{*}{ Period $^{\mathrm{a}}$} & \multirow[b]{3}{*}{ Child, Session } & \multicolumn{8}{|c|}{ Causal Connective by Cohesion Pattern } \\
\hline & & \multicolumn{2}{|c|}{ because } & \multicolumn{2}{|l|}{ so } & \multicolumn{2}{|l|}{ and } & \multicolumn{2}{|l|}{ Other } \\
\hline & & Child & Adult & Child & Adult & Child & Adult & Child & Adult \\
\hline \multirow[t]{5}{*}{ A } & Eric VI & 3 & 3 & 2 & - & 4 & - & - & - \\
\hline & Gia VII & - & 2 & 2 & - & 4 & - & - & - \\
\hline & Kathryn VI & 3 & 1 & 8 & - & 4 & - & 5 & - \\
\hline & Peter XVI & - & 2 & - & - & 3 & - & 1 & - \\
\hline & Totals & 6 & 8 & 12 & - & 15 & - & 6 & - \\
\hline \multirow[t]{5}{*}{ B } & Eric VIII & 2 & 7 & 5 & - & 5 & - & 5 & 1 \\
\hline & Gia VIII & - & - & 2 & - & 10 & - & 8 & - \\
\hline & Kathryn VIII & 19 & 17 & 17 & 3 & 4 & 1 & 14 & - \\
\hline & Peter XVIII & 6 & 7 & - & - & 5 & - & - & - \\
\hline & Totals & 27 & 31 & 24 & 3 & 24 & 1 & 27 & 1 \\
\hline \multirow[t]{6}{*}{$\mathrm{C}$} & Eric $\mathrm{X}$ & 4 & 9 & 7 & - & 5 & - & 6 & - \\
\hline & Gia XI & 17 & 25 & 3 & - & 7 & - & 7 & - \\
\hline & Kathryn X & 75 & 30 & 21 & 2 & 9 & 1 & 36 & - \\
\hline & Peter XIX & 13 & 9 & 1 & - & 6 & - & 3 & 1 \\
\hline & Totals & 109 & 73 & 32 & 2 & 27 & 1 & 52 & 1 \\
\hline & Overall Totals & 142 & 112 & 68 & 5 & 66 & 2 & 85 & 2 \\
\hline
\end{tabular}

aPeriods A, B, and C include the first, second, and third observation sessions in which the causative semantic relation was productive.

With the adversative relation, as seen in Table 6, child cohesion was most frequent; and and but were used with child cohesion first or with both cohesion patterns from the beginning.

\section{DISCUSSION}

The first syntactic connective the children learned, and, was also the most general: Syntactically, and was used in both contextual and syntactic structures; semantically, and was used to encode conjunction with all the different conjunction meaning relations in the order additive $<$ temporal $<$ causal $<$ adversative. Other syntactic connectives were learned subsequently, with different syntactic structures, and were semantically more specific. These results will be discussed in terms of form, and relative linguistic complexity in the adult model; content, and the intersection of form with conceptual and semantic factors affecting acquisition; and use, in terms of discourse cohesion.

\section{Form of Complex Sentences}

Two factors related to connective forms appeared to influence the developmental sequence of connectives and syntactic structures observed in this study. First, there seemed to be a conceptual constraint on learning syntactically homonymous forms (see also Bever, 1970). The first connectives the children learned were nonhomonymous (and, then, and because). The homonymous connectives except for when (what, where, that, and like), were learned in their nonconnective contexts first. When, in contrast, was learned as a connective long before it was learned as a $w h$-question form. 
Table 6. Frequency of Adversative Connectives According to Child and Adult Cohesion

\begin{tabular}{|c|c|c|c|c|c|c|c|}
\hline \multirow[b]{2}{*}{ Perioda } & \multirow{2}{*}{$\begin{array}{l}\text { Child } \\
\text { Session }\end{array}$} & \multicolumn{2}{|l|}{ but } & \multicolumn{2}{|l|}{ and } & \multicolumn{2}{|l|}{ Other } \\
\hline & & Child & Adult & Child & Adult & Child & Adult \\
\hline \multirow[t]{5}{*}{ A } & Eric VIII & 2 & 2 & 3 & - & - & - \\
\hline & Gia VII & - & - & 1 & 1 & - & 1 \\
\hline & Kathryn VI & 5 & 1 & - & - & - & - \\
\hline & Peter XVIII & - & 1 & 1 & - & - & - \\
\hline & Totals & 7 & 4 & 5 & 1 & $\mathrm{O}$ & 1 \\
\hline \multirow[t]{5}{*}{ B } & Eric $\mathrm{X}$ & 3 & 1 & 2 & - & 2 & - \\
\hline & Gia VIII & - & - & 3 & - & - & - \\
\hline & Kathryn VIII & 5 & 7 & - & - & - & - \\
\hline & Peter XIX & 3 & 1 & 4 & 2 & 1 & - \\
\hline & Totals & 11 & 9 & 9 & 2 & 3 & o \\
\hline \multirow[t]{7}{*}{$\mathrm{C}$} & Eric XII & 5 & 3 & 5 & - & 1 & - \\
\hline & Gia XI & 3 & 3 & 2 & - & - & - \\
\hline & Kathryn X & 19 & 49 & - & - & - & - \\
\hline & Peter XX & 4 & 1 & - & - & 1 & - \\
\hline & Totals & 31 & 56 & 7 & o & 2 & 0 \\
\hline & Overall & & & & & & \\
\hline & Totals & 49 & 69 & 21 & 3 & 5 & 1 \\
\hline
\end{tabular}

aPeriods A, B, and C include the first, second, and third observation sessions, respectively, in which the adversative semantic relation was productive.

The second factor had to do with the pronominalizing function of $w h$-forms. Harris (1957) described two functions of $w h$-forms in complex sentences: The forms who, what, where, when, which, as well as that can appear as pronominalizing connectives in the structure S1- $w h$-S2, and either (1) pronominalize an antecedent S1 noun, as in relativization (e.g., "There's a great hole where the bunny rabbits live") or (2) pronominalize a subject or object constituent of S2, as in complementation (e.g., "I don't know what this color is."). However, in the present study, when was the first $w h$-form to appear and functioned as a conjunction in temporal relations (as in "I'll get my slippers when I come out") rather than as a pronominalizing form. When functioned in the same way as and, because, so, and but functioned in additive, causal, and adversative sentences. The children in the present study learned the $\mathrm{S}_{1}$-wh-S $\mathrm{S}_{2}$ connective forms in the order when conjunction $<w h$-complement $<w h$-relative.

Of the class of complementizing morphemes discussed by Rosenbaum (1967) in his analysis of adult predicate complementation-that, for, to, and possessive -ing-only that (e.g., "Tell Iris that I wet my bed.") and to were observed in the children's speech. That was never a productive complementizer (although that was productive as a relative pronoun). The children did use pronominal $w h$-complementizers, which were not dealt with in Rosenbaum's analyses.

Syntactic Structures. Relativization, which occurred primarily with the main clause and required pronominalization of an antecedent noun, was the last structure the children learned. Complementation, which also involved pronominalization (of an S2 constituent) was learned before relativization and after conjunction (which did not involve pronominalization). The children learned complementation per se originally in the context of certain matrix verbs that took sentence complements without connectives (e.g., see, tell, want, know) and that appeared early in their speech along with simple sentences (see also Limber, 1973). For example, "see Mommy busy," "tell him wake up," and "I want man stand up" occurred before or at the same time as the first syntactic connective, the use of and to code additive conjunction. 
Table 7. Complement-taking Verbs

\begin{tabular}{|c|c|c|c|}
\hline & Epistemic & Notice & Communication \\
\hline \multicolumn{4}{|l|}{ Child Verbs } \\
\hline $\begin{array}{l}\text { Eric, Gia, Kathryn, } \\
\text { and Peter } \\
\text { (this study) }\end{array}$ & $\begin{array}{l}\text { know } \\
\text { think }\end{array}$ & $\begin{array}{l}\text { see } \\
\text { look } \\
\text { show } \\
\text { watch }\end{array}$ & $\begin{array}{c}\text { tell } \\
\text { ask } \\
\text { teach } \\
\text { explain }\end{array}$ \\
\hline Limber (1973) & $\begin{array}{l}\text { all the above and } \\
\text { guess } \\
\text { remember } \\
\text { wonder } \\
\text { decide } \\
\text { forget }\end{array}$ & all the above & $\begin{array}{l}\text { all the above, and } \\
\text { say }\end{array}$ \\
\hline \multicolumn{4}{|l|}{ Adult Verbs } \\
\hline Rosenbaum (1967) & $\begin{array}{l}\text { all the above, and } \\
\text { understand } \\
\text { believe } \\
\text { convince } \\
\text { surprise } \\
\text { doubt } \\
\text { worry } \\
\text { imagine } \\
\text { trust } \\
\text { recognize }\end{array}$ & $\begin{array}{c}\text { all the above, and } \\
\text { hear } \\
\text { observe }\end{array}$ & $\begin{array}{c}\text { all the above, and } \\
\text { admit } \\
\text { boast } \\
\text { promise } \\
\text { demonstrate } \\
\text { defy } \\
\text { persist } \\
\text { remind }\end{array}$ \\
\hline
\end{tabular}

The complementation the children learned with pronominalization was constrained by a small set of semantically specific state verbs, including know, think, see, watch, and tell, which were similar to verbs in the examples of child sentences reported by Limber (1973) and by Rosenbaum (1967) for adult complementation. A semantic distribution of the children's complement-taking verbs is presented in Table 7 along with verbs reported by Limber and by Rosenbaum. The children's later acquisition of epistemic, notice, and other verb complements with connectives appeared to be a formal development involving pronominalization.

With respect to conjunction, there are two hypotheses in transformational grammar for the derivation of phrasal conjunction, for example, "I want a green book and a pink book." In the more traditional analysis, phrasal conjunction is transformationally derived from an underlying base that contains two sentential structures, $\mathrm{S} \rightarrow$ $\mathrm{S}_{1}$ and $\mathrm{S}_{2}$ (or $\mathrm{NP}_{1} \mathrm{VP}_{1}$ and $\mathrm{NP}_{1} \mathrm{VP}_{2}$ ) with a general transformation that deletes the second $\mathrm{NP}_{1}$ (e.g., Chomsky, 1957; Gleitman, 1965; Stockwell, Schacter, \& Partee, 1973). This first hypothesis suggests the possibility that phrasal conjunction, which is transformationally more complex than sentential conjunction because of the deletion transformation, would be acquired by children after sentential conjunction (i.e., "I want a green book and I want a pink book"). This possibility has been supported in studies by Slobin and Welsh (1973) and Lust (1976). However, in the present study, phrasal structures appeared at the same time as (for three of the children) or before (for one of the children) sentential conjunction (as reported also by Bates, 1976, for Italian children, and by de Villiers, Tager-Flusberg, and Hakuta, 1977, and Lust and Mervis, 1980, for American children). These results are consistent with the second hypothesis concerning the derivation of phrasal conjunction: that the phrasal conjunction is itself basic in the underlying structure of the sentence (Stockwell, Schacter, \& Partee, 1973). Such phrases as "green book and pink book" are apparently learned as basic sentence constituents.

\section{Content of Complex Sentences}

A fuller explanation of the results of this study appears in the intersection of form with the semantic factors (the meaning relations between clauses and the meaning of connectives) and conceptual factors that affected 
acquisition. The children appeared to learn the connective and to begin with in order to express that two events simply go together in both phrasal structures (e.g., "I want to do a boy and a man") and sentential structures (e.g., "You do one and I do one"). The additive use of and was followed developmentally by sentences that combined clauses with different meaning relations between them-that is, temporal, causal, and adversative conjunction.

The developmental sequence of conjunction observed in this study cannot be compared with the results reported by Clancy, Jacobsen, and Silva (1976) because the two studies differed in methodology. They reported that coordination (additive conjunction) was always acquired first in the four languages they studied, but the sequence of antithesis (adversative), sequential, and causality was variable in the four languages (although antithesis always preceded causality). The sequence they reported for English was coordination $<$ sequence $<$ antithesis $<$ causality. Although language-specific factors no doubt influence the sequence of development, Clancy and her colleagues reported sequences of "complex meaning," whether or not a connective was expressed, and reported only the first instance of a category without a criterion of productivity. Also, the categories they described were not consistent with the categories in the present study; most notably, they considered that "the child's earliest notion of antithesis involves the rejection of one proposition and the assertion of an alternative" (p. 74). An example they gave was Nei, pot, meaning "no compote" in German, as the child rejected soup that was offered. Such instances of anaphoric negation would not have been included as instances of conjunction in the study reported here.

The general cumulative principle that was used to decide on semantic interpretation proved to characterize the developmental sequence in which the semantic subcategories of conjunction appeared (see Brown \& Hanlon, 1970, for discussion of syntactic cumulative complexity, and Brainerd, 1978, for discussion of cumulative complexity in cognitive development). In the developmental sequence additive $<$ temporal $<$ causal $<$ adversative, the temporal, causal, and adversative sentences were all additive in that two events or states were joined; causal was both additive and temporal; some of the adversative sentences were additive, temporal, and quasi-causal (e.g., "I was trying to get my crayons but I fell"-meaning "I couldn't get my crayons because I fell"). Adversative sentences included the new meaning of opposition or contrast (e.g., "I have a puppet/but not a real puppet").

The sequence of semantic development also has an analogue in children's conceptual development: Children learn to form collections of things (e.g., Sinclair, 1970) before they learn to form series of things that are ordered relative to one another (e.g., Inhelder \& Piaget, 1959/1964). The children in this study learned to talk about things that go together (additive conjunction) before they learned to talk about things that go together in ordered relationship (temporal, causal, and adversative conjunction).

\section{Cohesion of Complex Sentences}

The cohesion analysis in the present study provided evidence that learning increasingly complex structures is not dependent upon or otherwise the result of reciprocity in discourse, as has been claimed, for example, by Greenfield and Smith (1976). The two clauses with complex meaning relations that have been described were expressed most often by the child (child-child cohesion). Adult-child or child-adult-child cohesion, which occurred most often in expressions of causality or adversative relations, was always less frequent than child-child cohesion with the same semantic relations and increased developmentally. The development of adult-child cohesion reflected the children's increasing ability to participate in discourse, using newly or already learned linguistic forms, rather than the learning of linguistic forms through discourse. It appears that children have to learn something about the forms of language before learning the situational and interpersonal constraints on using such forms, as has been suggested with respect to children's alternating use of nominal and pronominal forms (Bloom, Lightbown, \& Hood, 1975) and temporal deixis with the use of verb inflections (Bloom, Lifter, \& Hafitz, 1980).

\section{CONCLUSIONS}

The considerable difficulty involved in learning complex sentences can be inferred from the length of time covered by the results of the study reported here. Evidence of sudden insight or 'across the board' learning was not apparent in the present study. On the contrary, approximately 8-week intervals (for Peter) and 12-week 
intervals (for Eric, Gia, and Kathryn) separated each of the observations that provided the data for analysis, and the linguistic gains observed were small, although consistent, across the entire time span of this study. Although there were intervening observations available (since approximately every other observation was used), the data for these observations did not appear (on the basis of cursory scanning) to conflict in any way with the general picture of slow but steady progress toward the acquisition of complex sentences. Moreover, this acquisition can be described only in terms of emergence, as the children presented evidence of learning something about the forms and functions of complex sentences, rather than in terms of achievement. The procedures used for inferring acquisition were considerably more conservative than those used in other studies (inasmuch as criteria for acquisition included more than use of a single instance of a structure by a single child, as had been the case in other studies; e.g., Bates, 1976; and Clancy, Jacobsen, \& Silva, 1976). Nevertheless, it was clear that the children had only just begun to learn about the use of syntactic connectives and meaning relations in conjunction, complementation, and relativization structures.

There was consistency among the children in the sequence in which the different meaning relations emerged and were expressed in complex sentences, but variation among them in the sequence in which they acquired different connectives to encode these meanings. This result-variation in form with similarity in content in the development of individual children-is consistent with reports of other aspects of these children's language acquisition (see Bloom, Lightbown, \& Hood, 1975, on nominal/pro-nominal variation and early sentence relations; Hood \& Bloom, 1979, on clause order in expressions of causality; and Bloom, Lifter, \& Hafitz, 1980, on acquisition of -ed/irregular verb inflections). The variation in age of emergence (of connectives and meaning relations) that was observed is consistent with the consensus in the child language literature that age alone is a poor predictor of acquisition.

To conclude, at least three factors influence the acquisition of syntactic connectives and the sequence of development of complex sentences with these connectives: the pronominalization of major constituents, the use of homonymous forms, and cumulative semantic complexity. Additionally, the children did not learn complex sentences by connecting their own utterance with a prior adult utterance to form the two clauses of a complex sentence. Rather, the informational requirements of the content of the children's messages appeared to be a stronger influence than discourse requirements for determining the form of the children's complex sentences with syntactic connectives.

\section{REFERENCES}

Bates, E. (1976). Language in context. New York: Academic Press.

Bever, T. (1970). The cognitive basis for linguistic structures. In J. Hayes (Ed.), Cognition and the development of language (pp. 279-352). New York: Wiley.

Bloom, L., \& Capatides, J. (1987). Sources of meaning in complex syntax: The sample case of causality. Journal of Experimental Child Psychology, 43, 112-28.

Bloom, L. (1970). Language development: Form and function in emerging grammars. Cambridge, MA: MIT Press.

Bloom, L. (1978). The semantics of verbs in child language. Address to Eastern Psychological Association, Washington, D.C.

Bloom, L. (1992). Racism in developmental research. President's Message, Division 7 Newsletter. Washington, DC: American Psychological Association, Fall-Winter.

Bloom, L., \& Lahey, M. (1978). Language development and language disorders. New York: Wiley.

Bloom, L., Lifter, K., \& Hafitz, J. (1980). Semantics of verbs and the development of verb inflection in child language. Language, 56, 386-412.

Bloom, L., Lightbown, P., \& Hood, L. (1975). Structure and variation in child language. Monographs of the Society for Research in Child Development, 40 (serial no. 160). 
Brainerd, C. (1978). The stage question in cognitive-developmental theory. Behavioral and Brain Sciences, 2, 173-213.

Brown, R., \& Hanlon, C. (1970). Derivational complexity and order of acquisition in child speech. In J. Hayes (Ed.), Cognition and the development of language (pp. 11-53). New York: Wiley.

Brown, R. (1973). A first language, the early stages. Cambridge, MA: Harvard University Press.

Chomsky, N. (1957). Syntactic structures. The Hague: Mouton.

Clancy, P., Jacobsen, T., \& Silva, M. (1976). The acquisition of conjunction: A cross-linguistic study. Papers and reports on child language development (No. 12, December, pp. 71-80). Department of Linguistics, Stanford University.

Clark, E. (1970). How young children describe events in time. In G. Flores d'Arcais \& W. Levelt (Eds.), Advances in psycholinguistics (pp. 275- 84). New York: American Elsevier.

Clark, E. (1973). How children describe time and order. In C. Ferguson \& Slobin (Eds.), Studies of child language development (pp. 585-606). New York: Holt, Rinehart \& Winston.

de Villiers, J., Tager-Flusberg, H., \& Hakuta K. (1977). Deciding among theories of the development of coordination in child speech. Papers and reports on child language development (No. 13, pp. 118-25). Department of Linguistics, Stanford University.

Ferreiro, E., \& Sinclair, H. (1971). Temporal relationships in language. International Journal of Psychology, 6, 39-47.

Gleitman, L. (1965). Coordinating conjunctions in English. Language, 41, 260-93.

Greenfield, P., \& Smith, J. (1976). The semantics of communication in early language development. New York: Academic Press.

Halliday, M., \& Hasan, R. (1976). Cohesion in English. London: Longman Group (English Language Series).

Harris, Z. (1957). Cooccurrence and transformations in linguistic structure. Language, 33, 283-340.

Hood, L., \& Bloom, L. (1979). What, when, and how about why: A longitudinal study of early expressions of causality. Monographs of the Society for Research in Child Development, 44 (serial no. 6).

Hood, L., Lahey, M., Lifter, K., \& Bloom, L. (1978). Observational descriptive methodology in studying child language: Preliminary results on the development of complex sentences. In G. Sackett (Ed.), Observing behavior. Vol. 1: Theory and applications in mental retardation. Baltimore MD: University Park Press.

Inhelder, B., \& Piaget, J. (1959/1964). The early growth of logic in the child. New York: Norton.

Jespersen, O. (1961). A modern English grammar on historical principles (vol. 5). London: Allen \& Unwin. (Originally published between 1909 and 1949)

Limber, J. (1973). The genesis of complex sentences. In T. Moore (Ed.), Cognitive development and the acquisition of language (pp. 169-85). New York: Academic Press.

Lust, B. (1976). Conjunction reduction in the language of young children. Paper presented at the Second Annual Boston University Conference on Language Development.

Lust, B., \& Mervis, C. (1980). Development of coordination in the natural speech of young children. Journal of Child Language, 7, 279-304.

Menyuk, P. (1969). Sentences children use. Cambridge, MA: MIT Press.

Rosenbaum, P. (1967). The grammar of English predicate complement constructions. Cambridge, MA: MIT Press.

Schlesinger, I. (1971). Production of utterances and language acquisition. In D. Slobin (Ed.), The ontogenesis of grammar (pp. 63-101). New York: Academic Press. 
Sinclair, H. (1970). The transition from sensory-motor behavior to symbolic activity. Interchange, 1, 119-26.

Slobin, D., \& Welsh, C. (1973). Elicited imitation as a research tool in developmental psycholinguistics. In C. Ferguson \& D. Slobin (Eds.), Studies of child language development (pp. 485-97). New York: Holt, Rinehart \& Winston.

Stockwell, R., Schachter, P., \& Partee, B. (1973). The major syntactic structures of English. New York: Holt, Rinehart \& Winston. 